particular reason to adopt a different position. I think that insertion of the catheter is then expedited and the effects of position are minimized. I am not convinced that clinically important aortocaval compression is more common in the lateral decubitus position than in the sitting position.

Terrance W. Breen MD FRCPC

Department of Anesthesia

Foothills Hospital

1403 - 29th Street NW

Calgary, AB T2N 2T9

REFERENCE

1 Andrews PJD, Ackerman WE, Jumeja MM. Aortocaval compression in the sitting and lateral decubitus positions during extradural catheter placement in the parturient. Can J Anaesth 1993; 40: 320-4

\section{Epidural catheter entrapment}

To the Editor:

We recently encountered a case of difficulty in removal of an epidural catheter that gave us some insight into a possible mechanism of entrapment.

The patient was a $150 \mathrm{~cm}$ tall 26 -yr-old para 0 gravida 1 patient weighing about $69 \mathrm{~kg}$, who requested epidural anaesthesia for relief of pain of labour. The initial advancement of a \#16 Tuohy needle at interspace $L_{3-4}$ struck bone. The needle was partially withdrawn and again advanced several times with the tip pointing progressively cephalad until the epidural space was identified by loss of resistance to air. Drugs infused through the catheter provided adequate pain relief for labour and delivery. In the post-partum period, we were unable to remove the catheter despite various manoeuvres such as flexing and twisting the patient's back and injecting refrigerated sterile saline through the catheter. Repeat attempts were made over two days before the catheter was able to be removed on the third day with vigorous traction.

Reviewing the manoeuvres of identifying the epidural space with the Tuohy needle suggests a mechanism of entrapment of the epidural catheter. The proposed mechanism is illustrated in Figures 1 to 3. In Figure 1, initial advancement of the epidural needle has traversed the interspinous ligaments and struck bone at location "X." In Figure 2 the needle is partially withdrawn, angled progressively more cephalad and advanced forming two new tracks. After the epidural needle is advanced through the ligament flavum and a catheter is passed, it is withdrawn. This allows the tissues that had been compressed to recoil

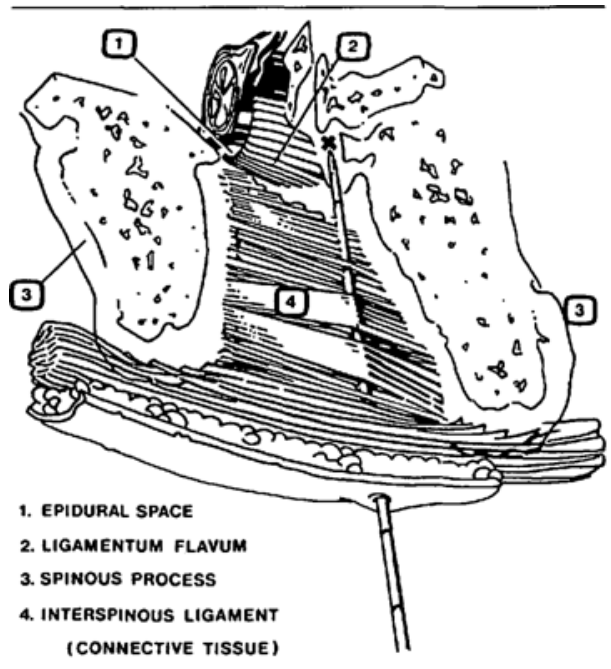

FIGURE 1 A coronal view through the midline at $\mathrm{L}_{3}-\mathrm{L}_{4}$. The epidural needle is advanced and strikes the base of the spinous process at "X."

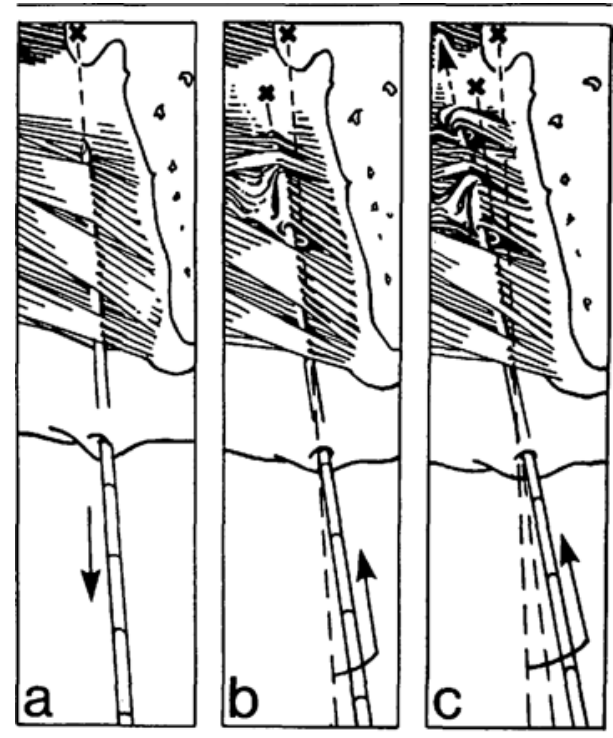

FIGURE 2 Left panel: partial retraction of the needle. Middle panel: needle is angulated and displaced cephalad but it still strikes bone. Right panet. needle is again partially retracted, further angulated and displaced oephalad. 


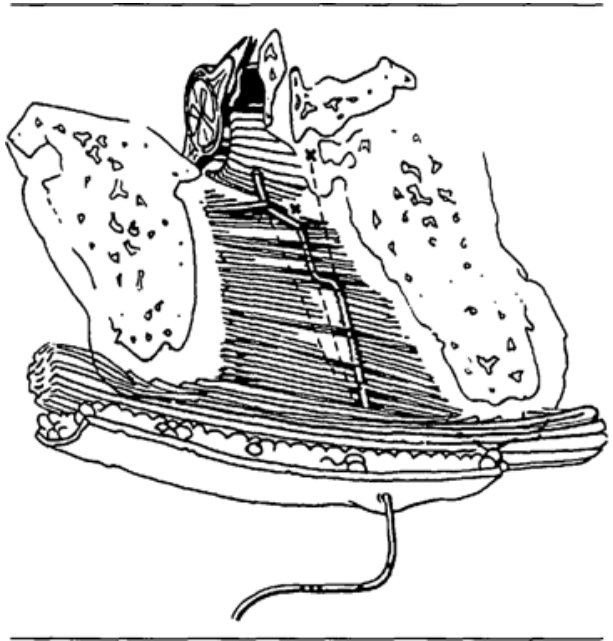

FIGURE 3 After passing catheter through the reedle, the epidural needle is withdrawn. The tissues recoil angulating the catheter.

resulting in a series of angulations in the catheter (Figure 3). At the time of removal of the catheter, the force caused by traction on the catheter would be progressively reduced distal to each bend leading to tendency to distal catheter entrapment. We reproduced the method of insertion of the catheter using a dense foam material to stimulate the soft tissues of the back and this resulted in a configuration of the catheter as illustrated in the figures.

Epidural catheter entrapment is rare and not amenable to investigation through trials. We therefore bring this hypothesized mechanism to the attention of our colleagues who may add to these observations. It is important to know if further observations support this mechanism for entrapment as it is easily avoidable by withdrawing the needle to the skin prior to changes in direction of advancement.

Joseph A. Fisher MD FRCPC

Chidambarm Ananthanaravan MD FRCPC

Department of Anaesthesia

Mount Sinai Hospital

Toronto, Ontario 